\title{
TXNIP in Agrp Neurons Regulates Adiposity, Energy Expenditure, and Central Leptin Sensitivity
}

\author{
Clemence Blouet, Shun-Mei Liu, Young-Hwan Jo, Streamson Chua, and Gary J. Schwartz \\ Departments of Medicine and Neuroscience of The Albert Einstein College of Medicine, Bronx, New York 10461
}

Thioredoxin interacting protein (TXNIP) has recently been described as a key regulator of energy metabolism through pleiotropic actions that include nutrient sensing in the mediobasal hypothalamus (MBH). However, the role of TXNIP in neurochemically specific hypothalamic subpopulations and the circuits downstream from MBH TXNIP engaged to regulate energy homeostasis remain unexplored. To evaluate the metabolic role of TXNIP activity specifically within arcuate Agrp neurons, we generated Agrp-specific TXNIP gain-offunction and loss-of-function mouse models using Agrp-Ires-cre mice, TXNIP floxfflox mice, and a lentivector expressing the human TXNIP isoform conditionally in the presence of Cre recombinase. Overexpression of TXNIP in Agrp neurons predisposed to diet-induced obesity and adipose tissue storage by decreasing energy expenditure and spontaneous locomotion, without affecting food intake. Conversely, Agrp neuronal TXNIP deletion protected against diet-induced obesity and adipose tissue storage by increasing energy expenditure and spontaneous locomotion, also without affecting food intake. TXNIP overexpression in Agrp neurons did not primarily affect glycemic control, whereas deletion of TXNIP in Agrp neurons improved fasting glucose levels and glucose tolerance independently of its effects on body weight and adiposity. Bidirectional manipulation of TXNIP expression induced reciprocal changes in central leptin sensitivity and the neural regulation of lipolysis. Together, these results identify a critical role for TXNIP in Agrp neurons in mediating diet-induced obesity through the regulation of energy expenditure and adipose tissue metabolism, independently of food intake. They also reveal a previously unidentified role for Agrp neurons in the brain-adipose axis.

\section{Introduction}

Thioredoxin interacting protein (TXNIP) was first described as a protein that binds with high affinity to thioredoxin, a major ubiquitously expressed thiol-reducing nonenzymatic antioxidant, and that inhibits thioredoxin's ability to reduce sulfhydryl groups via NADPH oxidation (Nishiyama et al., 1999). Structurally, TXNIP belongs to the poorly characterized $\alpha$-arrestin protein family, a subgroup of the arrestin clan proteins (Alvarez, 2008; Aubry et al., 2009).

Recent findings provide evidence for a role for TXNIP as an important regulator of glucose and lipid metabolism through pleiotropic actions that include regulation of $\beta$-cell function, hepatic glucose production, peripheral glucose uptake, adipogenesis, and substrate utilization (Bodnar et al., 2002; Hui et al., 2004, 2008; Sheth et al., 2005; Parikh et al., 2007; Chutkow et al., 2008;

Received Jan. 23, 2012; revised May 23, 2012; accepted May 26, 2012.

Author contributions: C.B., Y.-H.J., S.C., and G.J.S. designed research; C.B. and Y.-H.J. performed research; S.-M.L. and S.C. contributed unpublished reagents/analytic tools; C.B.,Y.-H.J., and G.J.S. analyzed data; C.B. and G.J.S. wrote the paper.

We thank Dr. Joel Elmquist (University of Texas Southwestern Medical Center) for providing Agrp-ires-Cre mice, and Drs. William Chutkow and Richard Lee (Brigham and Women's Hospital and Harvard Medical School) for providing the hTXNIP plasmids and TXNIP flox/flox mice. This work was supported by a grant to C.B. from the American Heart Association (AHA 09POST2100135) and grants to G.J.S. from the National Institutes of Health (DK026667 and DK020541).

The authors declare no competing financial interests.

Correspondence should be addressed to Drs. Clemence Blouet and Gary J. Schwartz, Departments of Medicine \& Neuroscience, Albert Einstein College of Medicine, 1300 Morris Park Avenue, Golding 501, Bronx, NY 10461. E-mail: clemence.blouet@einstein.yu.edu; gary.schwartz@einstein.yu.edu.

DOI:10.1523/JNEUROSCI.0353-12.2012

Copyright $\odot 2012$ the authors $\quad 0270-6474 / 12 / 329870-08 \$ 15.00 / 0$
Shalev, 2008). TXNIP expression is induced in conditions of nutrient excess, and this induction has been implicated in the pathogenesis of diabetes both in rodent models and in humans (Hui et al., 2004; Parikh et al., 2007; Chen et al., 2008b; Chutkow et al., 2008). Underlying mechanisms were first thought to depend on TXNIP's well described ability to negatively regulate the bioavailability of thioredoxin, but emerging evidence suggests that some of TXNIP's effects rely on a thioredoxin-independent $\alpha$-arrestinconserved role in metabolism, potentially through the regulation of endosome formation and protein ubiquitination (Patwari et al., 2009, 2011; Chutkow and Lee, 2011).

Our recent data indicate that TXNIP's diverse physiological roles in the regulation of metabolism include nutrient sensing in discrete brain areas relevant to the central control of energy homeostasis, including the mediobasal hypothalamus $(\mathrm{MBH})$, which comprises the arcuate nucleus of the hypothalamus (ARH) and the ventromedial nucleus of the hypothalamus. TXNIP is minimally expressed outside these discrete nutrient-sensing nuclei, and TXNIP expression responds to signals of acute and chronic energy availability exclusively in the $\mathrm{MBH}$ (Blouet and Schwartz, 2011). In this brain nucleus, similarly to what has been reported in the pancreas, liver, and adipose tissue (Chen et al., 2008a; Chutkow et al., 2008, 2010), TXNIP expression is suppressed by acute signals of energy availability (refeeding) but induced in conditions of chronic overnutrition (high-fat feeding) (Blouet and Schwartz, 2011). Virally mediated, bidirectional modulations of MBH TXNIP expression in adult mice maintained on a high-fat diet produced complementary consequences on body weight, adiposity, and glycemic control, supporting a 
role for MBH TXNIP in the mechanisms by which signals of energy availability affect whole-body energy metabolism (Blouet and Schwartz, 2011).

While implicating MBH TXNIP in the regulation of energy homeostasis and the etiology of diet-induced obesity, these studies thus far have not provided insight into the function of TXNIP in neurochemically specific hypothalamic subpopulations and in the circuits activated downstream from MBH TXNIP to regulate energy homeostasis in high-fat fed animals.

In the current work, we hypothesized that TXNIP in Agrp neurons, a subpopulation of $\mathrm{MBH}$ neurons strongly implicated in the regulation of energy balance (Cone, 1999), contributes to the metabolic phenotype induced by MBH-wide TXNIP manipulations. To test this hypothesis, we developed Agrp-specific TXNIP gain-offunction and loss-of-function mutants and assessed the effects of Agrp-specific TXNIP upregulation and loss of function on multiple behavioral and metabolic contributors to energy balance.

\section{Materials and Methods}

Animals. All experimental protocols were approved by the Institute for Animal Studies of the Albert Einstein College of Medicine. Mice were single-housed or group-housed in a temperature-controlled environment at $22-24^{\circ} \mathrm{C}$ under a $12 \mathrm{~h}$ light $/ 12 \mathrm{~h}$ dark cycle, and fed either standard chow or 35\% high-fat diet (D12450B and D12451B respectively, Research Diets). Water was provided ad libitum.

Transgenic mice. Agrp-Ires-cre mice, in which a DNA cassette containing an internal ribosome entry site (IRES) followed by the coding sequence for Cre recombinase inserted at a site located $3 \mathrm{bp}$ after the Agrp stop codon, were kindly provided by Dr. Joel Elmquist (University of Texas Southwestern Medical Center) and obtained as described previously (Fukuda et al., 2008). Agrp-Ires-cre mice were genotyped with the following primers: 5'-GGGCCCTAAGTTGAGTTTTCCT-3' , 5' -GATTACCCAA CCTGGGCAGAA C-3' ${ }^{\prime}$, and 5'-GGGTCGCTACAGACGTTGTTT G-3' .

Txnip flox/flox mice, with an exon1 loxP-flanked Txnip locus, were kindly provided by Drs. William Chutkow and Richard Lee (Brigham and Women's Hospital and Harvard Medical School) and obtained as described previously (Yoshioka et al., 2007). Txnip flox/flox mice were genotyped using the following primers: F1-sense $5^{\prime}$-TTTCGTTTGGGT TTTCAAGC-3'; F2-sense, 5'-CTTCACCCCCCTAGAGTGAT-3'; and R-antisense, 5' -CCCAGAGCACTTTCTTGGAC-3', to detect wild-type, flox, and deleted TXNIP alleles.

LepR-GFP mice were obtained as previously described (van de Wall et al., 2008).

NPY-GFP mice [B6.FVB-Tg(Npy-hrGFP)1Lowl/J; stock number 006417] were obtained from The Jackson Laboratory.

NPY-GFP;Agrp-Ires-Cre mice were obtained by crossing NPY-GFP mice with Agrp-Ires-cre mice.

Generation of Agrp-TXNIP knock-out mice. To selectively knock out TXNIP in Agrp neurons, we used the Cre/Lox technology. Agrp-Ires-cre mice show a high Cre activity restricted to Agrp neurons in the arcuate nucleus of the hypothalamus (Fukuda et al., 2008) where TXNIP is highly expressed (Blouet and Schwartz, 2011). We bred Txnip ${ }^{\text {floxfflox }}$ mice to Agrp-Ires-cre mice to obtain double heterozygotes that were bred to each other to obtain Txnip $p^{\text {flox/flox; }}$ Agrp-Ires-cre mice. Both males and females were used for the subsequent studies. Mice detected to be homozygous deleted for Txnip in tissues used for genotyping were excluded. Txnip flox/flox $^{\text {; Agrp-Ires-cre mice }}$ were born with the expected Mendelian ratio, had no detectable developmental defects, and were fertile (average litter size, eight pups).

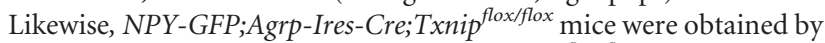
crossing NPY-GFP;Agrp-Ires-Cre mice with Txnip flox/flox mice.

hTXNIP lentiviral particles. Human TXNIP (hTXNIP) and C247S hTXNIP (mutant that does not bind to thioredoxin, used as control) plasmids (provided by Drs. William Chutkow and Richard Lee, Brigham and Women's Hospital and Harvard Medical School), were prepared as previously described (Blouet and Schwartz, 2011).

hTXNIP-flox lentiviral plasmid. A lentiviral construct previously developed to express hTXNIP (Patwari et al., 2006) and provided by Drs.
William Chutkow and Richard Lee (Brigham and Women's Hospital and Harvard Medical School) was modified for conditional expression. The lentiviral vector (pCDH-CMV-MCS-EF1-Puro, System Biosciences) had the hTXNIP cDNA cloned between the NheI and EcoRI sites, part of the multiple cloning sequence after the CMV promoter. A transcriptional blocking sequence flanked by loxP sites was amplified with $\mathrm{T} 3$ and T7 primers from a construct MC4R-loxTB provided by Dr. Joel Elmquist (Balthasar et al., 2005). The amplicon was digested with SalI and XhoI followed by a fill-in reaction for blunt-end ligation into the XbaI site of the hTXNIP plasmid, similarly filled in to generate a blunt end. Several loxTB-containing plasmids were screened and verified by sequencing the amplified segment. Plasmids were subsequently used for packaging reactions to generate viral stocks suitable for transfection by System Bioscience.

Generation of Agrp TXNIP overexpressing mice. To selectively overexpress TXNIP in Agrp neurons, we used the Cre/Lox technology. Using stereotaxic surgery, we injected the hTXNIP-flox lentivirus into the mediobasal hypothalamus of male Agrp-Ires-cre mice and wild-type male littermates. Under ketamine/xylazine anesthesia, mice were injected with lentiviral particles $\left(1-2 \times 10^{9} \mathrm{pfu} / \mathrm{ml}, 500 \mathrm{nl} /\right.$ side over a $10 \mathrm{~min}$ period; injection rate, $50 \mathrm{nl} / \mathrm{min}$ ) as previously described (Blouet et al., 2009). At the end of the experiment, all mice were killed by decapitation and mediobasal hypothalamic wedges were systematically dissected as previously described (Blouet et al., 2009). Total RNA was isolated from frozen $\mathrm{MBH}$ wedges using RNeasy Mini Kit (Quiagen) according to the manufacturer's instructions. Extracted RNA was quantified using a NanoDrop ND-1000 (Nanodrop) and RNA integrity was confirmed with ethidium bromide staining. Following treatment with DNase I (Invitrogen), purified RNA was used as template for first-strand cDNA synthesis using SuperScript III (Invitrogen). Quantitative real-time RT-PCR was run using LC-Fast Start DNA SYBR Green I chemistry (Roche Diagnostics) on a LightCycler 2.0 platform (Roche Diagnostics). Samples contained 2 $\mu \mathrm{l}$ of Fast Start DNA Master SYBR Green I, $4 \mathrm{~mm} \mathrm{MgCl}_{2}$, and $0.5 \mu \mathrm{M}$ of each primer in a $20 \mu \mathrm{l}$ final volume. To ascertain deletional activation of hTXNIP expression, we chose a forward primer in the sequence between the CMV transcription start site and the LoxTB cassette (CGCCAAGCTCGAAATTAACCCTCA), and a reverse primer in the hTXNIP coding sequence (TCTCGCCACTGCCGTACACCT; expected product size of the hTXNIP deleted transcript, $386 \mathrm{bp}$ ). PCR products were analyzed on agarose gel.

Stereotaxic cannula implantation. Stereotaxic surgery to target the $\mathrm{MBH}$ was performed under ketamine/xylazine anesthesia as previously described (Blouet et al., 2009). Briefly, mice were stereotaxically implanted with a steel guide cannula (Plastics One) into the third ventricle (coordinates from bregma: anteroposterior, $-0.3 \mathrm{~mm}$; dorsoventral, -3 $\mathrm{mm}$ ), or with a bilateral cannula targeting the $\mathrm{MBH}$ (coordinates from bregma: anteroposterior, $-1.1 \mathrm{~mm}$; dorsoventral, $-5.9 \mathrm{~mm}$; center-center, 0.8 $\mathrm{mm})$. Animals were allowed 1 week to recover. Correct cannula placement was confirmed histologically postmortem by India ink injections of $50 \mathrm{nl}$ $(\mathrm{MBH})$ or $500 \mathrm{nl}$ (intracerebroventricular).

Metabolic phenotyping. Body weight was measured weekly. Body composition was determined by magnetic resonance spectroscopy (MRS) using an echo MRS instrument (Echo Medical Systems). To determine energy expenditure, mice were adapted to individual metabolic chambers. Metabolic measurements (oxygen consumption, carbon dioxide production, food intake, and locomotor activity) were obtained continuously using a CLAMS (Columbus Instruments) open-circuit indirect calorimetry system for 7 consecutive days.

Glycemic control. Glucose tolerance was assessed with a $1 \mathrm{~g} / \mathrm{kg}^{-1}$ body weight oral glucose challenge after a 6 h daytime fast with tail blood sampling. Insulin sensitivity was assessed using an intraperitoneal $0.75 \mathrm{U}$ insulin challenge after a $6 \mathrm{~h}$ daytime fast with tail blood sampling.

Intracerebroventricular leptin sensitivity test. After a $2 \mathrm{~h}$ food deprivation, mice received an intracerebroventricular injection of 0.5 or $1 \mu \mathrm{g}$ of leptin (R\&D Systems) or vehicle (saline) in $1 \mu \mathrm{l}, 1 \mathrm{~h}$ before the onset of the dark period, in a cross-over design, and we measured $24 \mathrm{~h}$ body weight change in food intake.

Intracerebroventricular melanotan II challenge. Central melanotan II (MTII) challenges were adapted from (Shrestha et al., 2010). After a $2 \mathrm{~h}$ 
food deprivation in the morning, mice received an intracerebroventricular injection of $1 \mu \mathrm{g}$ of MTII (Bachem) or vehicle (saline) in $1 \mu \mathrm{l}$, in a cross-over design. Blood samples were collected at $0,30,60,90$, and 120 min for biochemical analyses.

Analytical procedures. We determined blood glucose levels using a glucometer (Precision Xtra, MediSense), plasma insulin using an ELISA (Alpco), and plasma nonesterified fatty acid (NEFA) and glycerol using colorimetric assays (Wako and Cayman, respectively).

Tissue collection for immunostaining and immunostaining. Mice were anesthetized using pentobarbital. Brains were perfused transcardially and processed as previously described (Blouet et al., 2009). Coronal hypothalamic sections of $30 \mu \mathrm{m}$ thickness were prepared on a freezing microtome and free-floating sections were incubated with $1 \%$ hydrogen peroxide for $10 \mathrm{~min}$ and washed 3 times for $10 \mathrm{~min}$ with PBS before the following treatments. Sections were blocked $2 \mathrm{~h}$ with $5 \%$ normal goat antiserum (NGS) and incubated in TXNIP antiserum (1:500, MBL International) with $0.3 \%$ Triton X-100 and 5\% NGS in PBS for $24 \mathrm{~h}$ with gentle agitation. Sections were exposed for $2 \mathrm{~h}$ to cy3-conjugated goat anti-mouse (1:400; Jackson Immunoresearch), washed in PBS, floated onto gelatinized slides, and coverslipped with Vectashield (Vector Laboratories). For pSTAT3 immunofluorescence, we used mice implanted with a bilateral cannula into the MBH. Mice were perfused $30 \mathrm{~min}$ after an intra-MBH leptin treatment ( $100 \mathrm{ng} /$ side in $100 \mathrm{nl}$ in $1 \mathrm{~min}$ ). Following $\mathrm{H}_{2} \mathrm{O}_{2}$ treatment, slices were rinsed $10 \mathrm{~min}$ in $0.3 \%$ glycine, $10 \mathrm{~min}$ in $0.03 \%$ SDS , and $10 \mathrm{~min}$ in methanol with $0.3 \%$ glycine and $0.03 \%$ SDS. Sections were blocked $2 \mathrm{~h}$ with 5\% NGS and incubated in pSTAT3 antiserum (1:500, Tyr705, Cell Signaling Technology \#9145) with 0.3\% Triton X-100 and 5\% NGS in PBS for $48 \mathrm{~h}$ with gentle agitation. Sections were exposed for $2 \mathrm{~h}$ to Alexafluor 594 goat-anti-rabbit (1:1000; Invitrogen) washed in PBS, floated onto gelatinized slides, and coverslipped with Vectashield (Vector Laboratories). Because the native GFP signal from the NPY-GFP and LepR-GFP mice we used is very bright, GFP fluorescence was visualized without antibody staining. Fluorescence was visualized with the appropriate lasers and emission filters on a Leica SP2 confocal microscope. Images were analyzed using ImageJ software and plugins from Montpellier RIO Imaging (http://www.mri.cnrs.fr).

RT-PCR analysis. RNA extraction, preparation, and real-time PCR experiments were performed as previously described (Blouet et al., 2008). Quantitative real-time RT-PCR was run using FastStart Universal Probe Master on a 480 Lightcycler (Roche Diagnostics). Primers and hydrolysis probes used were as follows: Agrp, forward primer TTTGTC CTCTGAAGCTGTATGC, reverse primer GCATGAGGTGCCTCCC TA, Roche hydrolysis probe \#32; NPY, forward primer CCGCTCTGCG ACACTACAT, reverse primer TGTCTCAGGGCTGGATCTCT, Roche hydrolysis probe \#9; POMC, forward primer AGTGCCAGGACCTCAC CA, reverse primer CAGCGAGAGGTCGAGTTTG, Roche hydrolysis probe \#62; actin, forward primer CTAAGGCCAACCGTGAAAAG, reverse primer ACCAGAGGCATACAGGGACA, Roche hydrolysis probe \#64. Relative quantification of each transcript compared with $\beta$-actin was determined as previously reported (Blouet et al., 2008).

Slice preparation. Transverse brain slices were prepared from mice at postnatal age 8-9 weeks. Animals were anesthetized with a mixture of ketamine and xylazine. After decapitation, the brain was transferred into a sucrose-based solution bubbled with $95 \% \mathrm{O}_{2}$ and $5 \% \mathrm{CO}_{2}$ and maintained at $\sim 3^{\circ} \mathrm{C}$. This solution contained the following (in mM): 248 sucrose, $2 \mathrm{KCl}, 1 \mathrm{MgCl}_{2}, 1.25 \mathrm{KH}_{2} \mathrm{PO}_{4}, 26 \mathrm{NaHCO}_{3}$, and 10 glucose. Transverse coronal brain slices $(200 \mu \mathrm{M})$ were prepared using a Vibratome (Leica VT1000S). Slices were equilibrated with an oxygenated artificial CSF (aCSF) for $>1 \mathrm{~h}$ before transfer to the recording chamber. The slices were continuously superfused with aCSF at a rate of $2 \mathrm{ml} / \mathrm{min}$ containing the following (in $\mathrm{mM}$ ): $113 \mathrm{NaCl}, 3 \mathrm{KCl}, 1 \mathrm{NaH}_{2} \mathrm{PO}_{4}, 26$ $\mathrm{NaHCO} 3,2.5 \mathrm{CaCl} 2,1 \mathrm{MgCl} 2$, and 5 glucose in $95 \% \mathrm{O}_{2}$ and $5 \% \mathrm{CO}_{2}$ at room temperature.

Electrophysiological recordings. Brain slices were placed on the stage of an upright, infrared-differential interference contrast microscope (Olympus BX50WI) mounted on a Gibraltar X-Y table (Burleigh) and visualized with a $40 \times$ water-immersion objective by infrared microscopy (Dage-MTI camera). Membrane potentials were recorded at $28^{\circ} \mathrm{C}$ to a $\mathrm{PC}$ after being filtered at $2 \mathrm{kHz}$ by a Multiclamp $700 \mathrm{~B}$ and analyzed using
pClamp10 (Axon). The external solution contained the following (in $\mathrm{mm}): 113 \mathrm{NaCl}, 3 \mathrm{KCl}, 1 \mathrm{NaH}_{2} \mathrm{PO}_{4}, 26 \mathrm{NaHCO}_{3}, 2.5 \mathrm{CaCl}_{2}, 1 \mathrm{MgCl}_{2}$, and 5 glucose in $95 \% \mathrm{O}_{2}$ and $5 \% \mathrm{CO}_{2}$. The internal solution contained the following (in $\mathrm{mM}$ ): 115 potassium acetate, $10 \mathrm{KCl}, 2 \mathrm{MgCl}_{2}, 10 \mathrm{EGTA}, 10$ HEPES, $2 \mathrm{Na}_{2} \mathrm{ATP}, 0.5 \mathrm{Na}_{2} \mathrm{GTP}$, and 10 phosphocreatine. Pipette resistance ranged from 3-4 M $\Omega$. We measured the membrane potential before, during, and after application of leptin $(50 \mathrm{nM})$ in current-clamp mode. After at least $5 \mathrm{~min}$ of stable recording, leptin was applied to the NPY neurons via bath application.

Statistical analysis. All data, presented as means \pm SEM, have been analyzed using GraphPad Prism 5. For all statistical tests, an $\alpha$ risk of 5\% was used. All kinetics were analyzed using repeated-measures two-way ANOVAs and adjusted with Bonferroni's post hoc tests. Multiple comparisons were tested with one-way ANOVAs and adjusted with Tukey's post hoc tests. Single comparisons were made using one-tail Student's $t$ tests.

\section{Results}

\section{TXNIP is expressed in NPY/Agrp neurons of the ARH}

Agrp and NPY are coexpressed in the ARH (Hahn et al., 1998; Haskell-Luevano et al., 1999; Grove and Smith, 2003). We first confirmed that TXNIP is expressed in NPY/Agrp neurons of the ARH using immunofluorescence labeling and confocal microscopy in NPY-GFP mice. We found that $>90 \%$ of NPY neurons express TXNIP (Fig. 1A).

\section{Overexpression of TXNIP in Agrp neurons predisposes toward diet-induced obesity}

To selectively overexpress TXNIP in Agrp neurons, we used stereotaxic surgery to inject male Agrp-Ires-cre mice and their wildtype littermates with an hTXNIP-flox lentivirus bilaterally into the MBH. This manipulation led to the expression of the hTXNIP mutant selectively in Agrp neurons of adult Agrp-Ires-cre mice.

Induction of hTXNIP expression in Agrp neurons significantly increased body weight gain when animals were maintained on a high-fat diet $(1.68 \pm 0.61 \mathrm{~g} / \mathrm{d}$ vs $2.68 \pm 0.84 \mathrm{~g} / \mathrm{d}$, respectively in WT and Agrp-Ires-cre mice injected with the hTXNIP-flox virus; main effect of genotype, $p=0.01$ ) (Fig. $1 B$ ). Body weights significantly differed beginning 4 weeks after the viral injection $(p=0.04)$ due to increased fat mass $(p=0.02$ at 6 weeks; $p=$ 0.01 at 18 weeks) and without any difference in fat-free mass (Fig. $1 C, D)$. TXNIP overexpression in Agrp neurons did not affect daily food intake (data not shown). Instead, nighttime energy expenditure was dramatically reduced, as evidenced by the lower oxygen consumption rate $(p=0.0008)$ and the decreased locomotor activity level ( $p=0.0008)$ in Agrp-Ires-cre mice injected with the hTXNIP-flox virus (Fig. $1 E, G$ ). In addition, nighttime respiratory quotient was significantly lower in Agrp-Ires-cre mice than in controls $(p=0.0009)$ (Fig. $1 F)$. NPY, Agrp, and POMC mRNA expression did not significantly differ between groups 3 weeks after the viral injection (data not shown). Together, these results indicate that overexpression of TXNIP selectively in Agrp neurons predisposes to diet-induced obesity and adipose tissue storage by decreasing energy expenditure and spontaneous locomotion, without affecting food intake.

We next assessed the effect of Agrp TXNIP overexpression on glycemic control. In Agrp-Ires-cre mice and wild-type controls tested 12 weeks after the hTXNIP-flox virus injection, we found that TXNIP overexpression in Agrp neurons significantly impaired glucose tolerance and insulin sensitivity during an intraperitoneal insulin sensitivity test (main effect of genotype, $p=$ 0.03 , data not shown). Because at this stage, fat mass significantly differed between groups, we repeated these tests in a separate cohort 3 weeks after the virus injection, when body weight and fat 
A
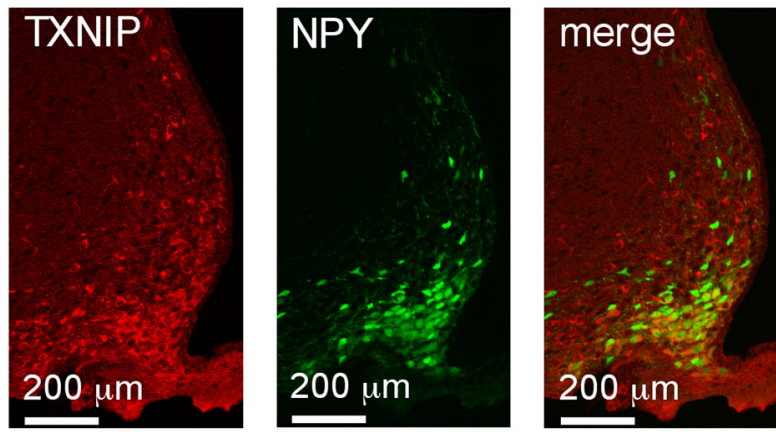

- - $\mathrm{hTXNIP-flox}$ virus in WT -hTXNIP-flox virus in Agrp-Ires-cre

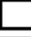

hTXNIP-flox virus in WT TXNIP-flox virus in Agrp-Ires-cre

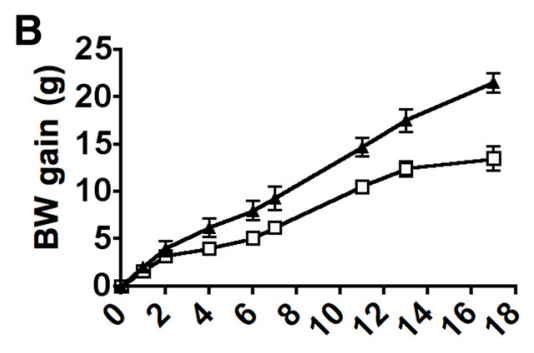

time after viral injection (wk)

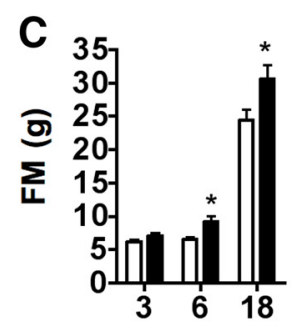

time after viral injection (wk)
E

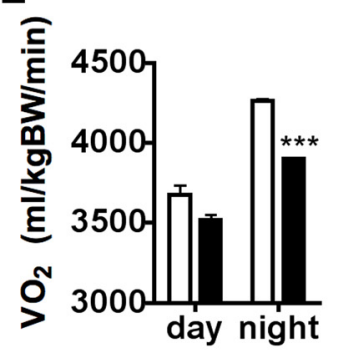

H

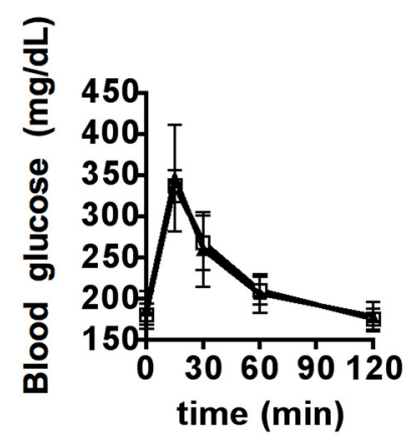

$\mathbf{F}$

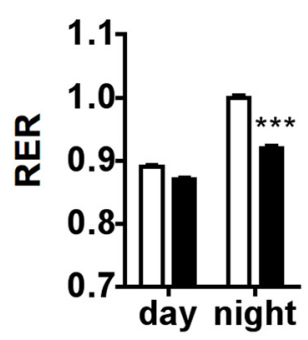

I

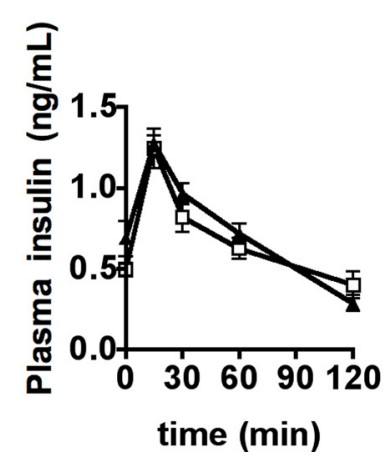

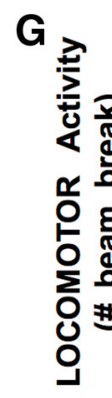

$\mathrm{J}$

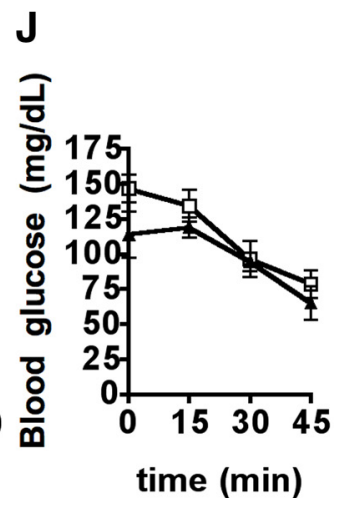

Figure 1. Overexpression of TXNIP in Agrp neurons predisposes toward diet-induced weight gain and adiposity. $\boldsymbol{A}$, Colocalization (right, orange) of TXNIP (left, red) and NPY (middle, green) in the arcuate nucleus of the hypothalamus of NPY-GFP mice. $\boldsymbol{B}-\boldsymbol{J}$, Body weight gain $(\boldsymbol{B})$, fat mass $(\boldsymbol{C})$, fat-free mass $(\boldsymbol{D})$, oxygen consumption $(\boldsymbol{E})$, respiratory quotient $(\boldsymbol{F})$, spontaneous locomotor activity $(\boldsymbol{G})$, blood glucose and plasma insulin during an oral glucose tolerance test $(\boldsymbol{H}, \boldsymbol{I})$, and blood glucose during an intraperitoneal insulin sensitivity test $(\boldsymbol{J})$ in male Agrp-Ires-cre and wild-type mice injected with the hTXNIP-flox lentivirus into the mediobasal hypothalamus. Data are mean \pm SEM,$n=4-7 .{ }^{*} p<0.05 ;{ }^{* * *} p<0.001$.

mass did not yet significantly diverge. Glucose tolerance and intraperitoneal insulin sensitivity did not differ between groups at 3 weeks postviral injection (Fig. $1 \mathrm{H}, I, J$ ). Together these results indicate that TXNIP overexpression in Agrp neurons does not primarily affect glycemic control.

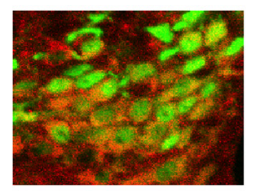

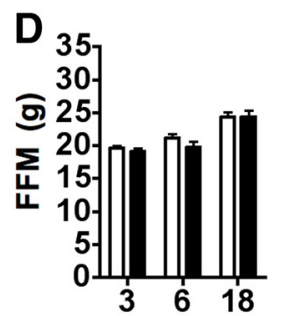

time after viral injection (wk)
Loss of TXNIP in Agrp neurons protects against diet-induced obesity High-fat diet maintenance promotes the development of obesity, and strongly induces TXNIP expression in the MBH of wild-type mice (Blouet and Schwartz, 2011). To further evaluate the role of TXNIP in Agrp-expressing neurons during high-fat diet maintenance, we bred Txnip flox/flox mice to Agrp-Ires-cre mice. Because Agrp-Ires-cre mice show high Cre activity restricted to Agrp neurons in the ARH (Fukuda et al., 2008), this manipulation leads to TXNIP-specific deletion in Agrp neurons of the ARH (Fig. 2A).

At birth, Txnip flox/flox; Agrp-Ires-cre mice had body weights similar to those of their wild-type counterparts. As shown in Figure 2, deletion of TXNIP in Agrp neurons decreased the rate of body weight gain in both males and females (main effect of genotype, $p=0.01$ in males and $p=0.04$ in females). Consequently, Txnip floxfflox; Agrp-Ires-cre mice had lower body weights than controls beginning at 12 weeks of age (Fig. 2B,E). This body weight difference was due to differences in fat mass (week 14, $p=0.02$ in males and $p=0.04$ in females) (Fig. 2C,F), and lean body mass did not significantly differ between groups (Fig. 2D,G). In males, Agrp neuronal TXNIP deletion did not significantly affect $24 \mathrm{~h}$ food intake (data not shown). In contrast, energy expenditure was markedly increased. At 10 weeks of age, when body weight and body fat mass did not yet differ between groups, oxygen consumption and nighttime locomotor activity were higher in Txnip $p^{\text {flox/flox }}$; AgrpIres-cre males compared with controls ( $p=0.01$ and $p=0.03$, respectively) (Fig. $2 \mathrm{H}, J)$. Substrate utilization, as determined by whole-body respiratory quotient, did not differ between groups (Fig. $2 I$ ). Together, these results indicate that Agrp neuronal TXNIP deletion protects against diet-induced obesity and adipose tissue storage by increasing energy expenditure and spontaneous locomotion, without affecting food intake.

Because MBH TXNIP knockdown improved glucose tolerance and insulin sensitivity (Blouet and Schwartz, 2011), we assessed glycemic control in 10week-old Txnip $p^{\text {flox/flox; }}$ Agrp-Ires-cre mice. We found a modest but significant decrease in 5-h-fast blood glucose levels in Txnip floxfflox; Agrp-Ires-cre mice compared to Txnip $p^{\text {flox/flox }}$ mice $(p=0.046)$ (Fig. $\left.2 K, M\right)$. Although blood glucose did not significantly differ between groups following an oral glucose challenge, plasma insulin levels at 15 min were lower in Txnip flox/flox; Agrp-Ires-cre mice than in

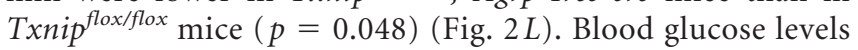


during an intraperitoneal insulin challenge did not differ between groups (Fig. $2 M$ ). These data indicate that Agrp TXNIP deletion improves glycemic control independently of its effects on body weight and adiposity.

TXNIP in Agrp neurons modulates central leptin sensitivity

Previous evidence indicates that $\mathrm{MBH}$ TXNIP regulates hypothalamic leptin's molecular, behavioral, and metabolic actions (Blouet and Schwartz, 2011). Leptin receptors are expressed in NPY/Agrp neurons within the arcuate nucleus of the hypothalamus (Mercer et al., 1996), and we confirmed that TXNIP is expressed in leptin-receptor-expressing neurons in the $\mathrm{MBH}$ (Fig. $3 A$ ), raising the possibility that TXNIP in Agrp neurons regulates the leptinergic control of energy balance. To test this hypothesis, we assessed the effects of Agrp-specific TXNIP gain or loss of function on central leptin action at stages where adiposity phenotypes were not yet present ( 3 weeks after the viral injection for Agrp-Ires-cre mice and wild-type controls injected with the hTXNIP-flox, and in 10-week-old Txnip flox/flox $^{\text {; Agrp-Ires-cre }}$ mice and controls). The feeding and metabolic responses to intracerebroventricular leptin were blunted in Agrp-Ires-cre mice injected with the hTXNIP-flox lentivirus compared controls (genotype effect for food intake and body weight gain, $p=0.01$ and $p=0.02$, respectively) (Fig. $3 B, C$ ). Conversely, Txnip flox/flox; Agrp-Ires-cre mice were more sensitive than controls to the behavioral and metabolic actions of centrally administered leptin (genotype effect for food intake and body weight gain, $p=0.044$ and $p=0.028$, respectively) (Fig. $3 D, E$ ). Together, these data indicate that TXNIP specifically in Agrp neurons bidirectionally modulates the behavioral response to central leptin.

To confirm these results in the context of TXNIP overexpression, we performed whole-cell patch-clamp recordings from NPY neurons of the ARH of NPY-GFP mice expressing hTXNIP or C247S hTXNIP (mutant used as a control) in the MBH. We found that $\mathrm{MBH}$ TXNIP overexpression blunts the electrophysiological impact of leptin on NPY neurons. Treatment with leptin (50 nM) to NPY neurons via bath application significantly hyperpolarized NPY neurons in controls, whereas leptin had no effect on NPY neurons in hTXNIP mice (Fig. $3 F$ ). Last, we measured leptin-induced p-STAT3 expression in Agrp neurons using NPY-GFP and NPY-GPF; Agrp-Ires-cre mice injected with the hTXNIP-flox virus and acutely treated with leptin directly into the MBH. pSTAT3 immunoreactivity was

B
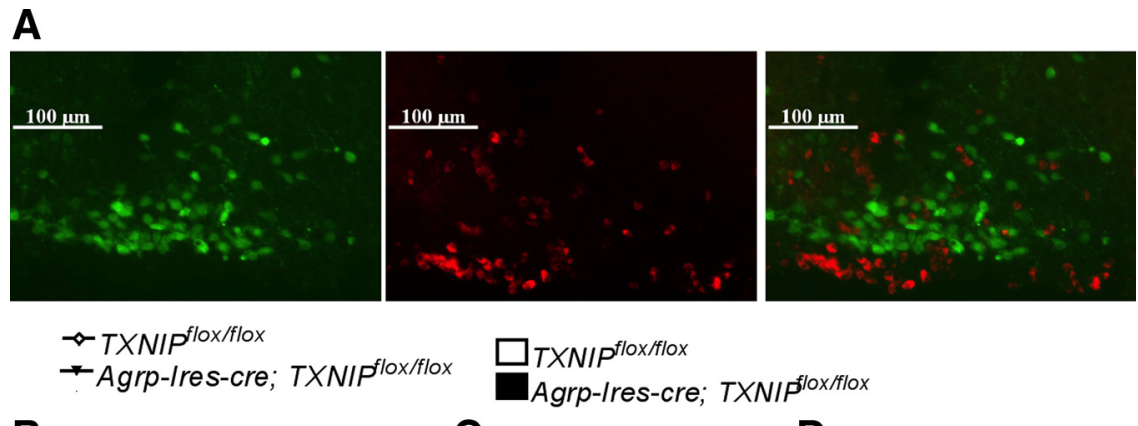
C
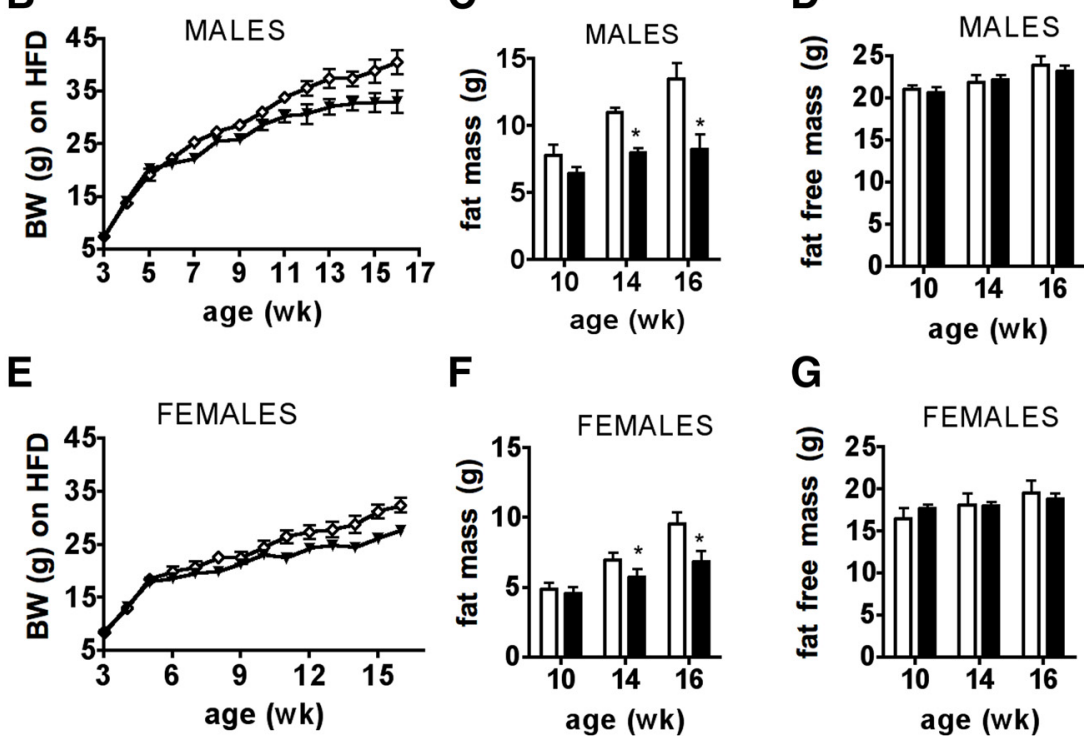

$\mathbf{F}$

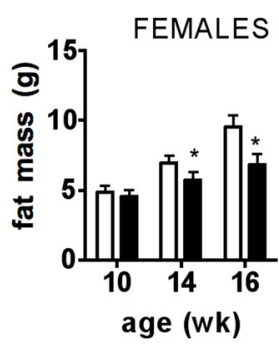

G
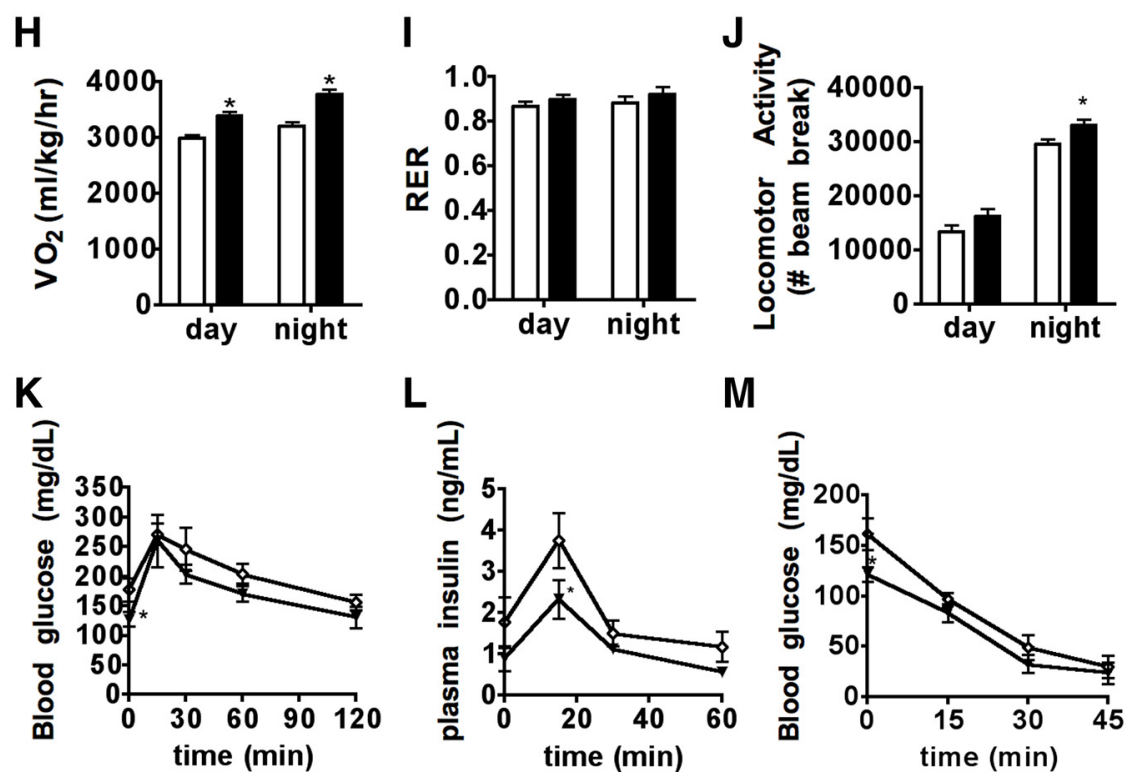

M
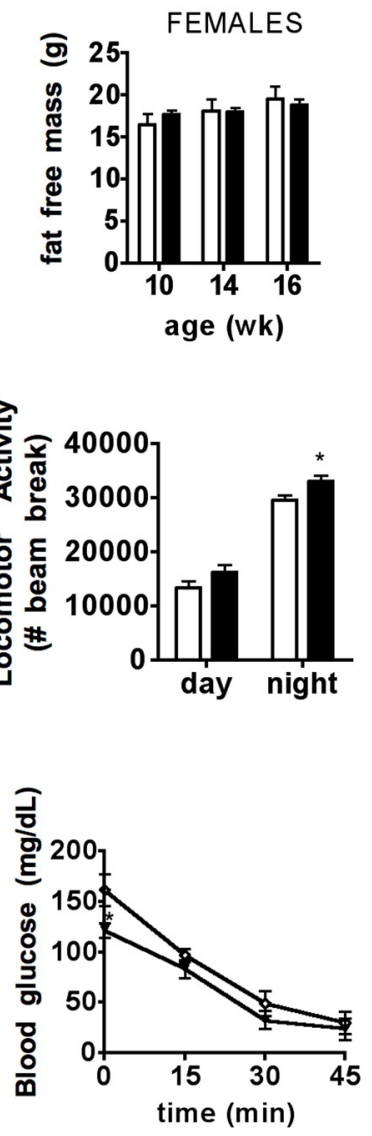

Figure 2. Knock-out of TXNIP in Agrp neurons protects against diet-induced weight gain and adiposity. $A$, Colocalization (right, yellow) of NPY (left, green) and TXNIP (middle, red) in Agrp-Ires-cre;NPY-GFP;TXNIfflox/flox mice. $\boldsymbol{B}-\boldsymbol{M}$, Body weight (B-E), fat mass $(\boldsymbol{C}-\boldsymbol{F})$, fat-free mass $(\boldsymbol{D}-\boldsymbol{G})$, oxygen consumption $(\boldsymbol{H})$, respiratory quotient $(\boldsymbol{I})$, locomotor activity $(\boldsymbol{J})$, blood glucose and plasma insulin during an oral glucose tolerance test $(\boldsymbol{K}, \boldsymbol{L})$, and blood glucose during an intraperitoneal insulin sensitivity test $(\boldsymbol{M})$ in TXNIPflox/flox; Agrp-Ires-cre and TXNIP flox/flox mice. Data are means \pm SEM, $n=4-8 .{ }^{*} p<0.05$. 
A

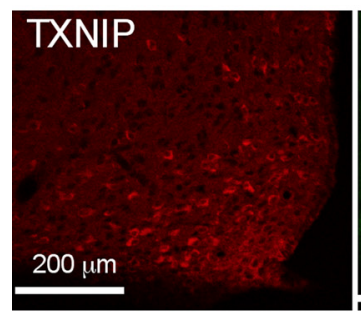

C

B

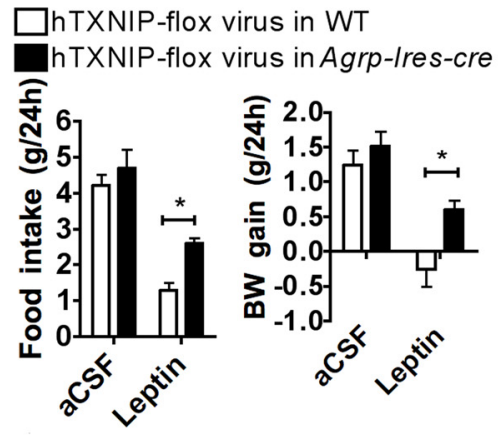

$\mathbf{F}$

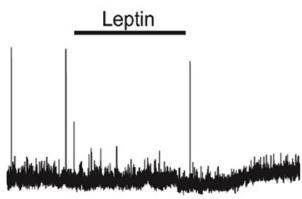

hTXNIP

G

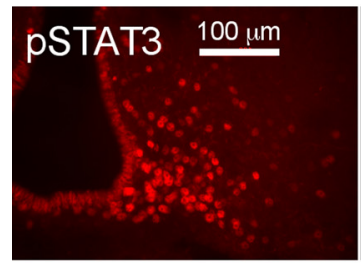

H

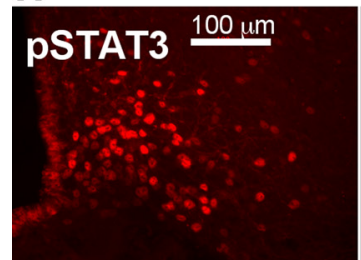

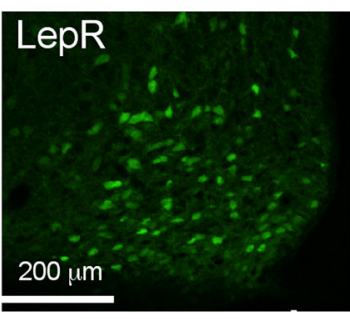

D

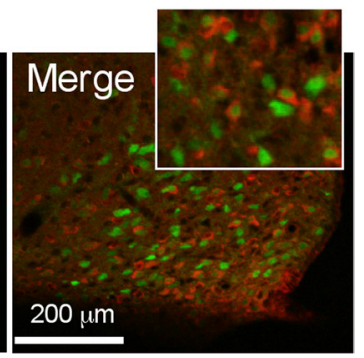

E

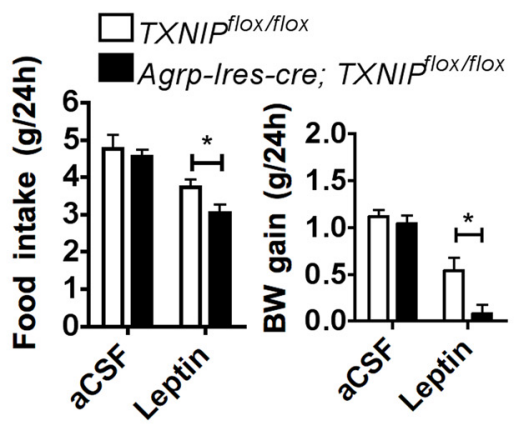

hTXNIP Control
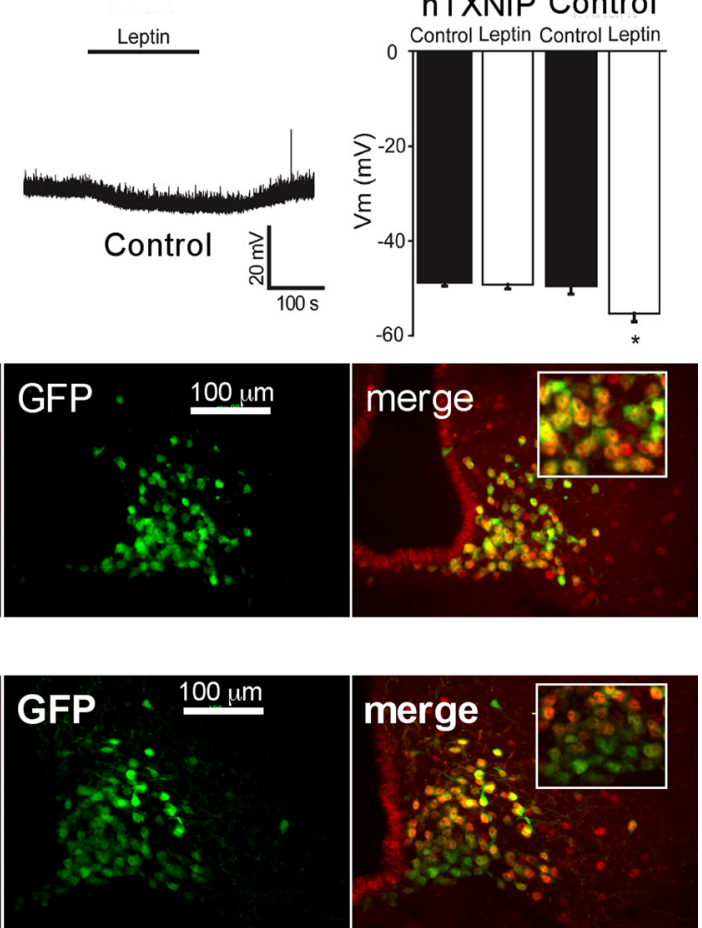

Figure 3. TXNIP in Agrp neurons bidirectionally regulates central leptin sensitivity. $\boldsymbol{A}$, Colocalization (right, orange) of TXNIP (left, red) and NPY (middle, green) in the mediobasal hypothalamus of LepR-GFP mice. B, C, Food intake and body weight gain in wild-type mice injected with the hTXNIP-flox lentivirus into the mediobasal hypothalamus. $\boldsymbol{D}, \boldsymbol{E}$, Food intake and body weight gain in TXNIPflox/flox; Agrp-Ires-cre and TXNIPflox/flox mice following a central injection of aCSF or leptin into the third ventricle. $\boldsymbol{F}$, Electrophysiological recordings from arcuate NPY neurons of animals expressing hTXNIP or controls in response to leptin stimulation. G, $\boldsymbol{H}$, Colocalization (right, yellow) of pSTAT3 (left, red) and GFP (middle, green) in NPY-GFP $(\boldsymbol{G})$ and NPY-GFP;Agrp-Ires-cre $(\boldsymbol{H})$ mice infected with the hTXNIP-flox lentivirus into the MBH. Data are means $\pm \mathrm{SEM}, n=7-8 .{ }^{*} p<0.05$.

Agrp neurons impairs the electrophysiological and molecular responses to leptin in Agrp neurons.

TXNIP in Agrp neurons contributes to the central control of adipose tissue metabolism

We then asked whether the above changes in leptin sensitivity following TXNIP gain and loss of function in Agrp neurons might alter the central melanocortinergic control of adipose tissue metabolism
(Song et al., 2005; Brito et al., 2007; Nogueiras et al., 2007), and thereby contribute to our observed changes in adiposity in the Agrp TXNIP loss-of-function and gain-of function mutations. To address this question, mice received a central MTII challenge, and MTII-induced changes in circulating NEFA and glycerol levels were measured. Tests were performed at stages at which adiposity did not yet differ between groups. Central administration of MTII significantly increased plasma NEFA and glycerol levels in control mice as early as $30 \mathrm{~min}$ after the injection (time effect, $p<0.0001$ for both NEFA and glycerol curves) (Fig. 4). In Agrp-Ires-cre mice injected with the hTXNIP-flox lentivirus, the MTII-induced NEFA and glycerol release was more robust than in controls (main effect of genotype, $p=0.012$ for the NEFA curves and $p=$ 0.015 for glycerol curves) (Fig. $4 A, B$ ). Conversely, in Txnip ${ }^{\text {flox/flox }}$; Agrp-Ires-cre mice, the lipolytic responses to MTII were blunted (main effect of genotype, $p=0.032$ for the NEFA curves and $p=0.048$ for the glycerol curves) (Fig. 4C,D).

To extend this result to a physiological situation of energy mobilization, we then tested whether TXNIP gain and loss of function in Agrp neurons also affected lipolysis during a $24 \mathrm{~h}$ period of food deprivation, a challenge known to activate Agrp neurons and induce lipolysis through sympathetic activation of adipose tissue (Hücking et al., 2003). In Agrp-Ires-cre mice injected with the hTXNIP-flox lentivirus, fasting-induced NEFA release and body weight loss were blunted compared with controls ( $p=$ 0.03 and $p=0.05$, respectively) (Fig. $4 E$ ). In contrast, TXNIP deletion in Agrp neurons increased fasting-induced NEFA release and body weight loss $(p=0.01$ and $p=0.02$, respectively) (Fig. $4 G$ ). These data confirm that TXNIP in Agrp neurons regulates the central control of lipolysis.

Last, because leptin signaling in Agrp neurons has been shown to regulate fastinginduced locomotor activity (Mesaros et al., 2008; van de Wall et al., 2008), we measured nighttime spontaneous locomotion following a $24 \mathrm{~h}$ fast. In Agrp-Ires-cre mice injected with the hTXNIP-flox lentivirus, the fasting-induced increase in nighttime locomotor activity was blunted ( $p=0.05)$ (Fig. $4 F)$. Conversely, in Agrp TXNIP knock-out mice, the fasting-induced increase in nighttime locomotor activity was increased ( $p=0.02$ ) (Fig. $4 H$ ). These results indicate that TXNIP in Agrp neurons also regulates the behavioral response to a fast.

\section{Discussion}

Our previous work identified TXNIP in the $\mathrm{MBH}$ as a novel contributor to hypothalamic nutrient sensing, and showed that $\mathrm{MBH}$ TXNIP activation in diet-induced obesity contributes to a 
A

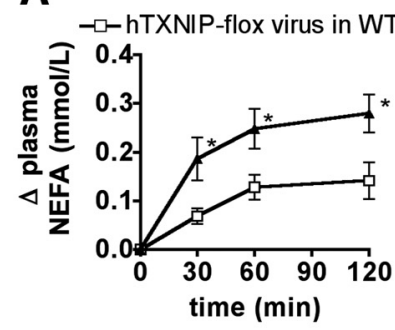

B

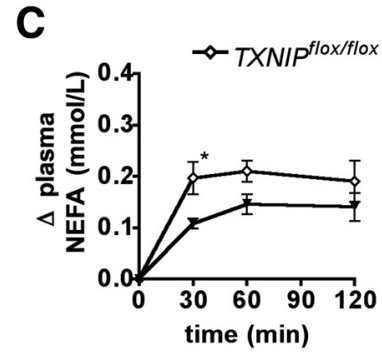

E

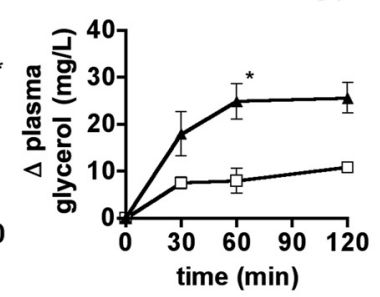

D

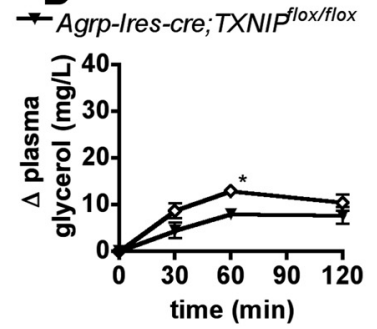

$\mathbf{F}$

hTXNIP-flox virus in Agrp-Ires-cre

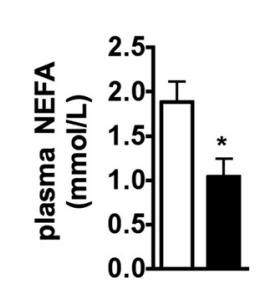

G

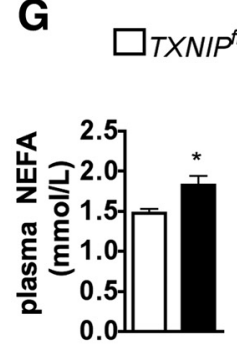

TXNIP flox/flox
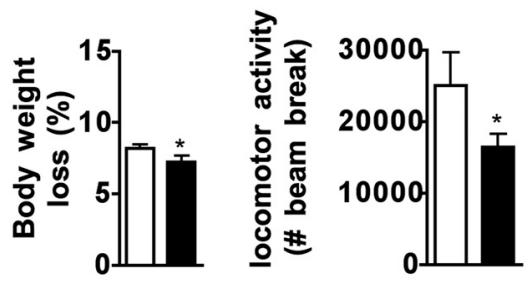

$\underset{\mathbf{D}_{\text {Agrp-Ires-cre; }}}{\mathbf{H}}$ TXNIIfioxffiox
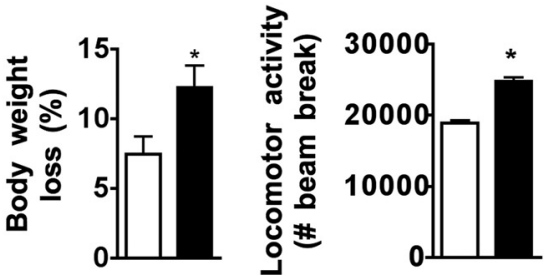

Figure 4. TXNIP in Agrp neurons bidirectionally mediates the melanocortinergic and fastinginduced controls of adipose tissue metabolism. $\boldsymbol{A}-\boldsymbol{D}, \Delta$ plasma NEFA $(\boldsymbol{A}, \boldsymbol{C})$ and $\Delta$ plasma glycerol ( $\boldsymbol{B}$, $D$ ) following central administration of MTIl into the third ventricle in male Agrp-Ires-cre and wild-type mice injected with the hTXNIP-flox lentivirus into the mediobasal hypothalamus $(\boldsymbol{A}, \boldsymbol{B})$, and following central administration of MTIl into the third ventricle in male TXNIPflox/flox; Agrp-Ires-cre and TXNIPflox/ flox mice $(\boldsymbol{C}, \boldsymbol{D})$. Data were corrected for values obtained after a vehicle injection. $\boldsymbol{E}-\boldsymbol{H}$, Effects of a $24 \mathrm{~h}$ fast on plasma NEFA, body weight loss $(\boldsymbol{E}, \boldsymbol{G})$, and nighttime locomotor activity $(\boldsymbol{F}, \boldsymbol{H})$ in male AgrpIres-cre and wild-type mice injected with the hTXNIP-flox lentivirus into the mediobasal hypothalamus $(\boldsymbol{E}, \boldsymbol{F})$ and in male TXNIPfoxfflox; Agrp-Ires-cre and TXNIP $P^{\text {floxflox }}$ mice $(\boldsymbol{G}, \boldsymbol{H})$. Data are means \pm SEM, $n=6-8 .{ }^{*} p<0.05$.

cluster of diet-induced metabolic dysfunctions, including increased body weight gain, adiposity, and impaired glycemic control. These findings left unresolved the roles of TXNIP in neurochemically specific subpopulations of the MBH. Here we (1) show that TXNIP colocalizes with NPY in the arcuate nucleus of the hypothalamus; (2) demonstrate that bidirectional changes in TXNIP expression in Agrp neurons produce complementary changes in body weight, adiposity, oxygen consumption, locomotor activity, and central leptin sensitivity; and (3) provide evidence supporting the conclusion that TXNIP in Agrp neurons bidirectionally regulates the central control of adipose tissue lipolysis. Together these results identify a critical role for TXNIP in Agrp neurons in mediating diet-induced obesity through the reg- ulation of energy expenditure and adipose tissue metabolism, independently of food intake. They also reveal that the major whole-body metabolic phenotypes arising from MBH TXNIP loss and gain of function can be accounted for by its actions in Agrp neurons.

Our results indicate that increased Agrp TXNIP expression is sufficient to produce energy imbalance in high-fat fed mice through a decrease in energy expenditure, evidenced by decreased oxygen consumption and physical activity, and in the absence of any effect on feeding behavior. Conversely, Agrp TXNIP knock-out provides resistance against diet-induced obesity through an increase in oxygen consumption and physical activity, without affecting food intake, supporting a role for endogenous Agrp TXNIP in the regulation of energy expenditure. Importantly, these changes have been measured before the onset of body weight and adiposity phenotypes, suggesting that TXNIP in Agrp neurons directly regulates oxygen consumption and locomotor activity, leading to changes in adiposity.

Agrp TXNIP gain and loss of function also induced reciprocal changes in central leptin sensitivity before the onset of adiposity phenotypes. Interestingly, leptin receptor knock-out in Agrp neurons increases body weight gain and adiposity through a decrease in energy expenditure and locomotor activity, without affecting food intake (van de Wall et al., 2008). Conversely, constitutive activation of STAT3 signaling in Agrp neurons reduces body weight gain and adiposity, increases oxygen consumption, and promotes spontaneous locomotor activity without changing feeding behavior (Mesaros et al., 2008). Therefore, we propose that changes in leptin sensitivity account for the changes in body weight gain, adiposity, energy expenditure, and locomotion following Agrp TXNIP gain and loss of function.

Leptin resistance has been shown to impair endogenous melanocortin tone, leading to compensatory hypersensitivity of melanocortin receptors to exogenous melanocortin activation (Scarpace et al., 2003). Because central melanocortin signaling is an important regulator of adipose tissue lipolysis (Song et al., 2005; Brito et al., 2007; Nogueiras et al., 2007), we used an MTII challenge to test whether changes in central leptin sensitivity following Agrp TXNIP gain and loss of function were associated with changes in the melanocortinergic regulation of adipose tissue lipolysis. As anticipated, overexpression of TXNIP in Agrp neurons increased the lipolytic response to central MTII administration, indicating decreased endogenous melanocortin input to adipose tissue in these mice and compensatory hypersensitivity to exogenous MTII. Consistently, fasting-induced lipolysis was lower in this group. Conversely, the decreased lipolytic response to central MTII administration in Agrp-Ires-cre; TXNIP flox/flox mice indicates increased endogenous melanocortin input to adipose tissue and compensatory hyposensitivity to exogenous MTII. Consistent with this conclusion, fasting-induced lipolysis was increased in this group. We propose that changes in central leptin sensitivity following Agrp TXNIP gain and loss of function account for these changes in the melanocortinergic control of adipose tissue lipolysis. These results implicate for the first time Agrp neurons in the brain-adipose axis. We propose that reduced lipolysis in situations of energy mobilization promotes adiposity in Agrp TXNIP-overexpressing mice, whereas increased lipolysis reduces adipose tissue storage in Agrp TXNIP knock-outs.

In summary, our work provides strong evidence favoring a role of increased Agrp TXNIP expression in diet-induced obesity through the regulation of central leptin sensitivity, energy expenditure, and adipose tissue metabolism. 


\section{References}

Alvarez CE (2008) On the origins of arrestin and rhodopsin. BMC Evol Biol 8:222.

Aubry L, Guetta D, Klein G (2009) The arrestin fold: variations on a theme. Curr Genomics 10:133-142.

Balthasar N, Dalgaard LT, Lee CE, Yu J, Funahashi H, Williams T, Ferreira M, Tang V, McGovern RA, Kenny CD, Christiansen LM, Edelstein E, Choi B, Boss O, Aschkenasi C, Zhang CY, Mountjoy K, Kishi T, Elmquist JK, Lowell BB (2005) Divergence of melanocortin pathways in the control of food intake and energy expenditure. Cell 123:493-505.

Blouet C, Schwartz GJ (2011) Nutrient-sensing hypothalamic TXNIP links nutrient excess to energy imbalance in mice. J Neurosci 31:6019-6027.

Blouet C, Ono H, Schwartz GJ (2008) Mediobasal hypothalamic p70 S6 kinase 1 modulates the control of energy homeostasis. Cell Metab $8: 459-467$

Blouet C, Jo YH, Li X, Schwartz GJ (2009) Mediobasal hypothalamic leucine sensing regulates food intake through activation of a hypothalamusbrainstem circuit. J Neurosci 29:8302-8311.

Bodnar JS, Chatterjee A, Castellani LW, Ross DA, Ohmen J, Cavalcoli J, Wu C, Dains KM, Catanese J, Chu M, Sheth SS, Charugundla K, Demant P, West DB, de Jong P, Lusis AJ (2002) Positional cloning of the combined hyperlipidemia gene Hyplip1. Nat Genet 30:110-116.

Brito MN, Brito NA, Baro DJ, Song CK, Bartness TJ (2007) Differential activation of the sympathetic innervation of adipose tissues by melanocortin receptor stimulation. Endocrinology 148:5339-5347.

Chen J, Saxena G, Mungrue IN, Lusis AJ, Shalev A (2008a) Thioredoxininteracting protein: a critical link between glucose toxicity and beta-cell apoptosis. Diabetes 57:938-944.

Chen J, Hui ST, Couto FM, Mungrue IN, Davis DB, Attie AD, Lusis AJ, Davis RA, Shalev A (2008b) Thioredoxin-interacting protein deficiency induces Akt/Bcl-xL signaling and pancreatic beta-cell mass and protects against diabetes. FASEB J 22:3581-3594.

Chutkow WA, Lee RT (2011) Thioredoxin regulates adipogenesis through thioredoxin-interacting protein (Txnip) protein stability. J Biol Chem 286:29139-29145.

Chutkow WA, Patwari P, Yoshioka J, Lee RT (2008) Thioredoxininteracting protein (Txnip) is a critical regulator of hepatic glucose production. J Biol Chem 283:2397-2406.

Chutkow WA, Birkenfeld AL, Brown JD, Lee HY, Frederick DW, Yoshioka J, Patwari P, Kursawe R, Cushman SW, Plutzky J, Shulman GI, Samuel VT, Lee RT (2010) Deletion of the alpha-arrestin protein Txnip in mice promotes adiposity and adipogenesis while preserving insulin sensitivity. Diabetes 59:1424-1434.

Cone RD (1999) The central melanocortin system and energy homeostasis. Trends Endocrinol Metab 10:211-216.

Fukuda M, Jones JE, Olson D, Hill J, Lee CE, Gautron L, Choi M, Zigman JM, Lowell BB, Elmquist JK (2008) Monitoring FoxO1 localization in chemically identified neurons. J Neurosci 28:13640-13648.

Grove KL, Smith MS (2003) Ontogeny of the hypothalamic neuropeptide Y system. Physiol Behav 79:47-63.

Hahn TM, Breininger JF, Baskin DG, Schwartz MW (1998) Coexpression of Agrp and NPY in fasting-activated hypothalamic neurons. Nat Neurosci $1: 271-272$.

Haskell-Luevano C, Chen P, Li C, Chang K, Smith MS, Cameron JL, Cone RD (1999) Characterization of the neuroanatomical distribution of agoutirelated protein immunoreactivity in the rhesus monkey and the rat. Endocrinology 140:1408-1415.

Hücking K, Hamilton-Wessler M, Ellmerer M, Bergman RN (2003) Burstlike control of lipolysis by the sympathetic nervous system in vivo. J Clin Invest 111:257-264.

Hui ST, Andres AM, Miller AK, Spann NJ, Potter DW, Post NM, Chen AZ, Sachithanantham S, Jung DY, Kim JK, Davis RA (2008) Txnip balances metabolic and growth signaling via PTEN disulfide reduction. Proc Natl Acad Sci U S A 105:3921-3926.

Hui TY, Sheth SS, Diffley JM, Potter DW, Lusis AJ, Attie AD, Davis RA (2004) Mice lacking thioredoxin-interacting protein provide evidence linking cellular redox state to appropriate response to nutritional signals. J Biol Chem 279:24387-24393.

Mercer JG, Hoggard N, Williams LM, Lawrence CB, Hannah LT, Morgan PJ, Trayhurn P (1996) Coexpression of leptin receptor and preproneuropeptide $\mathrm{Y}$ mRNA in arcuate nucleus of mouse hypothalamus. J Neuroendocrinol 8:733-735.

Mesaros A, Koralov SB, Rother E, Wunderlich FT, Ernst MB, Barsh GS, Rajewsky K, Brüning JC (2008) Activation of Stat3 signaling in AgRP neurons promotes locomotor activity. Cell Metab 7:236-248.

Nishiyama A, Matsui M, Iwata S, Hirota K, Masutani H, Nakamura H, Takagi Y, Sono H, Gon Y, Yodoi J (1999) Identification of thioredoxin-binding protein-2/vitamin $\mathrm{D}(3)$ upregulated protein 1 as a negative regulator of thioredoxin function and expression. J Biol Chem 274:21645-21650.

Nogueiras R, Wiedmer P, Perez-Tilve D, Veyrat-Durebex C, Keogh JM, Sutton GM, Pfluger PT, Castaneda TR, Neschen S, Hofmann SM, Howles PN, Morgan DA, Benoit SC, Szanto I, Schrott B, Schürmann A, Joost HG, Hammond C, Hui DY, Woods SC, et al. (2007) The central melanocortin system directly controls peripheral lipid metabolism. J Clin Invest 117:3475-3488.

Parikh H, Carlsson E, Chutkow WA, Johansson LE, Storgaard H, Poulsen P, Saxena R, Ladd C, Schulze PC, Mazzini MJ, Jensen CB, Krook A, Björnholm M, Tornqvist H, Zierath JR, Ridderstråle M, Altshuler D, Lee RT, Vaag A, Groop LC, et al. (2007) TXNIP regulates peripheral glucose metabolism in humans. PLoS Med 4:e158.

Patwari P, Higgins LJ, Chutkow WA, Yoshioka J, Lee RT (2006) The interaction of thioredoxin with Txnip. Evidence for formation of a mixed disulfide by disulfide exchange. J Biol Chem 281:21884-21891.

Patwari P, Chutkow WA, Cummings K, Verstraeten VL, Lammerding J, Schreiter ER, Lee RT (2009) Thioredoxin-independent regulation of metabolism by the alpha-arrestin proteins. J Biol Chem 284:24996-25003.

Patwari P, Emilsson V, Schadt EE, Chutkow WA, Lee S, Marsili A, Zhang Y, Dobrin R, Cohen DE, Larsen PR, Zavacki AM, Fong LG, Young SG, Lee RT (2011) The arrestin domain-containing 3 protein regulates body mass and energy expenditure. Cell Metab 14:671-683.

Scarpace PJ, Matheny M, Zolotukhin S, Tümer N, Zhang Y (2003) Leptininduced leptin resistant rats exhibit enhanced responses to the melanocortin agonist MT II. Neuropharmacology 45:211-219.

Shalev A (2008) Lack of TXNIP protects beta-cells against glucotoxicity. Biochem Soc Trans 36:963-965.

Sheth SS, Castellani LW, Chari S, Wagg C, Thipphavong CK, Bodnar JS, Tontonoz P, Attie AD, Lopaschuk GD, Lusis AJ (2005) Thioredoxininteracting protein deficiency disrupts the fasting-feeding metabolic transition. J Lipid Res 46:123-134.

Shrestha YB, Vaughan CH, Smith BJ Jr, Song CK, Baro DJ, Bartness TJ (2010) Central melanocortin stimulation increases phosphorylated perilipin A and hormone-sensitive lipase in adipose tissues. Am J Physiol Regul Integr Comp Physiol 299:R140-R149.

Song CK, Jackson RM, Harris RB, Richard D, Bartness TJ (2005) Melanocortin-4 receptor mRNA is expressed in sympathetic nervous system outflow neurons to white adipose tissue. Am J Physiol Regul Integr Comp Physiol 289:R1467-R1476.

van de Wall E, Leshan R, Xu AW, Balthasar N, Coppari R, Liu SM, Jo YH, MacKenzie RG, Allison DB, Dun NJ, Elmquist J, Lowell BB, Barsh GS, de Luca C, Myers MG Jr, Schwartz GJ, Chua SC Jr (2008) Collective and individual functions of leptin receptor modulated neurons controlling metabolism and ingestion. Endocrinology 149:1773-1785.

Yoshioka J, Imahashi K, Gabel SA, Chutkow WA, Burds AA, Gannon J, Schulze PC, MacGillivray C, London RE, Murphy E, Lee RT (2007) Targeted deletion of thioredoxin-interacting protein regulates cardiac dysfunction in response to pressure overload. Circ Res 101:1328-1338. 